\title{
PRÁTICAS GERENCIAIS DE PEQUENAS EMPRESAS INDUSTRIAIS DO ESTADO DE SÃO PAULO: UM ESTUDO EXPLORATÓRIO
}

\author{
Jaime Vogel, FGV-EAESP ${ }^{1}$ \\ Thomaz Wood Jr., FGV-EAESP²,
}

Resumo: Esta pesquisa objetivou verificar como proprietários e gestores de pequenas empresas industriais bem sucedidas definem práticas gerenciais, e ainda identificar quais práticas eles adotam. Foi realizado um estudo exploratório com quatro empresas, incluindo visitas às instalações, entrevistas e análise de documentos. $O$ estudo revelou características das pequenas empresas, tais como a informalidade nos processos, o acúmulo de funções, a centralização das decisões e a presença do proprietário na operação. $O$ estudo revelou também que os proprietários e gestores das empresas estudadas estão conscientes da importância das práticas gerenciais para o sucesso do negócio, o que se reflete na adoção de algumas práticas sofisticadas de gestão. No entanto, percebeu-se que as pequenas empresas abrem mão de certas práticas consideradas relevantes, por desconhecimento e falta de recursos, devido à atitude dos proprietários ou por considerarem a relação custo-benefício desvantajosa. A análise das práticas gerenciais nas áreas de planejamento estratégico, operações e logística, gestão de clientes, gestão da inovação, monitoramento e incentivos, gestão de recursos humanos, gestão financeira, relacionamento com grupos de interesse e sustentabilidade, permitiu compreender a realidade das pequenas empresas e seus desafios de gestão.

Palavras-chaves: Pequenas Empresas; Práticas Gerenciais; Profissionalização da Administração.

\section{MANAGERIAL PRACTICES IN MANUFACTURING SMALL FIRMS OF SÃO PAULO: AN EXPLORATORY STUDY}

Abstract: This research aimed to investigate how owners and managers of small manufacturing companies define successful management practices, and how they identify which practices they adopt. We conducted an exploratory study with four companies, including on-site visits, interviews and document analysis. The study

\footnotetext{
${ }^{1}$ E.mail: mr.vogeljaime@gmail.com

2 E.mail: thomaz.wood@fgv.br. Endereço: Avenida Nove de Julho, 2029, CEP 01313-902 São Paulo - SP
}

VOGEL, J.; WOOD JUNIOR, T. Práticas gerenciais de pequenas empresas industriais do Estado de São Paulo: um estudo exploratório. Revista de Empreendedorismo e Gestão de Pequenas Empresas, v. 1, n.2, 2012. 
revealed characteristics of small businesses, such as informal processes, the accumulation of functions, centralization of decisions and the presence of the owner in the operations. The study also revealed that the owners and managers of companies surveyed are conscious of the importance of management practices for business success, which is reflected in the adoption of some sophisticated management practices. However, we realized that small businesses open up certain practices deemed relevant by ignorance and lack of resources, because the attitudes of the owners or to consider the cost-benefit disadvantaged. The analysis of management practices in the areas of strategic planning, operations and logistics, customer management, innovation management, monitoring and incentives, human resource management, financial management, relationship with stakeholders and sustainability, enabled us to understand the reality of small businesses and their management challenges.

Keywords: Small Business; Management Practices; Professionalization of Management.

\section{Introdução}

Sabe-se que pequenas empresas têm grande relevância para a economia. Em 2008, de acordo com dados do Ministério do Trabalho e Emprego (MTE) consolidados pelo DIEESE, o Estado de São Paulo, no qual realizou-se o presente estudo, contava com 16.428 estabelecimentos industriais de pequeno porte ("pequenas empresas industriais"), os quais empregavam cerca de 690 mil pessoas. Tal contingente representava aproximadamente $8 \%$ dos empregos registrados no Estado (SEBRAE; DIEESE, 2010). Conforme critério adotado por estas instituições, são classificadas como pequena empresa industrial aquelas que possuem entre $20 \mathrm{e}$ 99 funcionários.

Por outro lado, são conhecidas as dificuldades que estas empresas enfrentam para sobreviver nos primeiros anos de existência. Estudo realizado pelo SEBRAESP em 2009 sobre mortalidade das empresas, revelou que 27\% das empresas constituídas no estado de São Paulo são encerradas em seu primeiro ano de existência. Segundo o mesmo levantamento, no quinto ano de atividade a taxa de mortalidade acumulada chega a $58 \%$, ou seja, somente $42 \%$ das empresas

VOGEL, J.; WOOD JUNIOR, T. Práticas gerenciais de pequenas empresas industriais do Estado de São Paulo: um estudo exploratório. Revista de Empreendedorismo e Gestão 
constituídas sobrevivem após o quinto ano de existência. De acordo com a avaliação dos empresários entrevistados na mesma pesquisa, os fatores mais importantes para a sobrevivência das empresas são o bom planejamento antes da abertura e uma boa gestão do negócio (SEBRAE, 2010).

Wood e Caldas (2007) argumentam que o desempenho competitivo de um sistema (país ou setor econômico) depende de três conjuntos de fatores: internos à empresa, estruturais e sistêmicos. Os fatores internos à empresa são aqueles sob o controle dos empresários e gestores. Compreendem recursos, habilidades adquiridas ou desenvolvidas ao longo da vida da empresa e da competência em gestão. Assim, o sucesso e a competitividade das empresas dependem em certa medida das práticas gerenciais.

O presente estudo, de natureza qualitativa exploratória, visou identificar como os empresários e gestores de pequenas empresas industriais bem sucedidas do Estado de São Paulo definem práticas gerenciais, e ainda explorar quais são as práticas adotadas em suas empresas. O restante do texto está estruturado da seguinte forma: a segunda seção apresenta o referencial teórico, focalizando a literatura sobre pequenas empresas; a terceira seção descreve o método de pesquisa, detalhando os critérios utilizados para seleção de casos e o processo de análise dos dados; a quarta seção apresenta os resultados da pesquisa; a quinta seção apresenta a discussão dos resultados; e a sexta seção apresenta a conclusão do trabalho.

\section{Importância das Práticas Gerenciais}

Por muito tempo, economistas especularam sobre os motivos para as variações existentes na produtividade e desempenho entre as empresas de um mesmo setor e entre as similares de países diferentes. Mesmo após a identificação de diversos fatores que influenciavam o desempenho, tais como capital, competências, tecnologia, dentre outros, restou uma parte substancial das

VOGEL, J.; WOOD JUNIOR, T. Práticas gerenciais de pequenas empresas industriais do Estado de São Paulo: um estudo exploratório. Revista de Empreendedorismo e Gestão 
diferenças, atribuídas por Bloom e Van Reenen (2007) à "qualidade de gestão" da empresa.

Chrisman, Bauerschmidt e Hofer (1998) analisaram 62 artigos sobre os fatores que influenciam o desempenho em novos empreendimentos e desenvolveram um modelo teórico em que o desempenho é função de variáveis relacionadas ao empreendedor, à estrutura da indústria, à estratégia de negócios, aos recursos e à estrutura da organização, contemplando sistemas e processos. Este último item, incluído no modelo, refere-se às práticas gerenciais, o que demonstra a influência destas sobre o desempenho dos novos empreendimentos.

Bloom e Van Reenen (2007) pesquisaram as práticas gerenciais de empresas de médio porte e explicaram porque nem todas as empresas adotam boas práticas, ainda que elas melhorem a produtividade. Um dos motivos é a relação de custobenefício, uma vez que as melhorias na gestão implicam em investimentos substantivos que às vezes podem superar os benefícios proporcionados. Outro motivo refere-se à questão de agência entre os gestores e os donos da empresa. A adoção de boas práticas pode não ser atrativa para os gestores, pois pode envolver um esforço maior para se alcançar os benefícios. Adicionalmente, a heterogeneidade entre as empresas faz com que haja variabilidade no grau de adoção de boas práticas gerenciais, pois o ótimo nível de adoção de boas práticas pode variar em função de diferentes custos e benefícios que cada empresa tem de acordo com suas características e o ambiente em que atua.

$\mathrm{Na}$ literatura acadêmica, até recentemente, eram raros os estudos empíricos sobre práticas gerenciais, isto porque não havia uma forma consistente de se fazer comparações entre empresas ou países. Bloom e Van Reenen (2007) buscaram preencher esta lacuna. Os pesquisadores desenvolveram em conjunto com uma grande empresa de consultoria, uma ferramenta de pesquisa sobre práticas gerenciais de empresas industriais, com um questionário semiestruturado abrangendo 18 diferentes práticas agrupadas em temas, tais como: gestão de finanças, metas de desempenho, inovação tecnológica, gestão da produção, recursos humanos, marketing e sustentabilidade.

VOGEL, J.; WOOD JUNIOR, T. Práticas gerenciais de pequenas empresas industriais do Estado de São Paulo: um estudo exploratório. Revista de Empreendedorismo e Gestão 
Nesta ferramenta, desenvolvida e aplicada a empresas de médio porte, boas práticas de gestão foram definidas como sendo aquelas que, na média, se mostravam boas para a produtividade das empresas e são consideradas benchmark no mercado. O questionário, aplicado às empresas por entrevistadores treinados, avaliou o grau de desenvolvimento em relação a dezoito práticas gerenciais, por meio de atribuição de notas para cada prática. O método foi aplicado em vários países, inclusive no Brasil (Brito; Wood, 2009; Padrão, Motta; Vieira, 2009), resultando em uma base de dados comparativa sobre práticas gerenciais das empresas industriais de médio porte.

Complementarmente ao questionário utilizado por Bloom e Van Reenen (2007) e adaptado no âmbito do projeto Observatório de Gestão da FGV-EAESP no Brasil (BRITO; WOOD, 2009), a presente pesquisa utilizou os critérios de excelência do Modelo de Excelência em Gestão (MEG) da Fundação Nacional da Qualidade (FNQ, 2010), e o questionário de avaliação de empresas utilizado no Prêmio MPE na estruturação do roteiro de entrevistas utilizado durante os estudos de caso.

\section{Práticas Gerenciais em Pequenas Empresas}

Com relação às pesquisas aplicadas, especificamente as práticas gerenciais de empresas de pequeno porte, os temas mais recorrentes são: gestão de recursos humanos, planejamento estratégico e financeiro, gestão da qualidade e indicadores de desempenho (XHENETI; BLACKBURN, 2010).

São também tratados na literatura outros aspectos voltados à gestão de empresas familiares, aplicáveis à maioria das pequenas empresas, tais como: problemas de agência, profissionalização da gestão, conflitos familiares, governança e processo sucessório (CHRISMAN et al., 2010, DEBICKI et al., 2009).

Contudo, a maior parte dos estudos refere-se a empresas de médio e grande porte. Portanto, embora a maioria das pequenas empresas tenha controle e gestão familiares, o estudo deste tipo de organização não permite por si só, compreender as especificidades das empresas de pequeno porte e suas características de gestão.

VOGEL, J.; WOOD JUNIOR, T. Práticas gerenciais de pequenas empresas industriais do Estado de São Paulo: um estudo exploratório. Revista de Empreendedorismo e Gestão 
De forma geral, as pesquisas sobre práticas gerenciais em pequenas empresas podem ser divididas em três grandes grupos temáticos: (1) da influência da liderança e das características dos proprietários sobre a organização, suas práticas gerenciais e a formação da cultura organizacional (ANDERSSON; TELL, 2009, REIJONEN; KOMPPULA, 2007); (2) da influência da estrutura organizacional, incluindo gestão de pessoas, grau de delegação de responsabilidades, profissionalização da gestão e alinhamento de incentivos (BARRINGER; JONES; NEUBAUM, 2005, GRAY, 2002); e (3) da relação entre as práticas gerenciais e o desempenho (MIZUMOTO et al., 2010, FENING; PESAKOVIC; AMARIA, 2008, SELS et al., 2006).

\section{Métodos}

Neste momento, vale lembrar que o objetivo primordial desta pesquisa foi verificar como os empresários e gestores de pequenas empresas industriais bem sucedidas definem práticas gerenciais, e ainda identificar quais práticas eles adotam. A estratégia de investigação, qualitativa e exploratória, consistiu na realização de estudos de caso em quatro pequenas empresas industriais, incluindo: visitas às instalações das empresas, entrevistas em profundidade com os proprietários e gestores e análise de documentos.

Todos os entrevistados têm um papel central na gestão das empresas e uma visão abrangente dos processos. As entrevistas foram conduzidas pessoalmente por um dos autores, com o apoio de um roteiro com questões abertas. O pesquisador se valeu de técnicas de construção de rapport ao longo da entrevista, buscando estabelecer uma relação de confiança com o entrevistado para, desta forma, conseguir informações relevantes e de qualidade (DUNDON; RYAN, 2010).

O roteiro estava dividido em duas partes: na primeira parte, perguntas abertas buscaram capturar a visão geral do entrevistado sobre o tema das práticas gerenciais; e na segunda parte foram abordadas as práticas gerenciais adotadas na empresa. Nesta segunda parte, as perguntas foram estruturadas a partir do 
questionário desenvolvido por Bloom e Van Reenen (2007) e adaptado por Brito e Wood (2009).

Nas visitas foi observado o processo fabril, o que permitiu compreender melhor as práticas adotadas. Os documentos analisados incluíram relatórios de desempenho e ordens de produção, entre outros, proporcionando um entendimento melhor dos processos e corroborando ou complementando informações coletadas durante as entrevistas.

A seleção das empresas foi realizada a partir dos seguintes critérios: pequeno porte; sede no Estado de São Paulo; mais de cinco anos de atuação no mercado; história de sucesso e lucratividade; destaque pelas práticas gerenciais; e taxa média de crescimento anual da receita superior a 10\% nos últimos três anos.

Foram utilizadas como fontes para a escolha: listas de empresas reconhecidas por sua qualidade de gestão, como no caso do Prêmio MPE promovido pela FNQ - Fundação Nacional da Qualidade; relatórios de pesquisa elaborados pela consultoria Delloitte em conjunto com a revista Exame PME sobre as pequenas e médias empresas que mais cresceram em 2010 e 2011; reportagens na mídia e contatos pessoais do pesquisador.

Uma lista inicial de 20 empresas foi preparada, passando em seguida por uma avaliação mais profunda quanto ao atendimento dos critérios. As empresas selecionadas foram então, convidadas a participar da pesquisa. A lista final constou de quatro empresas apresentadas a seguir:

- Atual Aquecimento Solar: empresa sediada em Mogi Guaçu - SP, fabricante de sistemas de aquecimento solar de água. Fundada em 1991, recebeu o Premio MPE Brasil na categoria indústria do Estado de São Paulo em 2010, sendo reconhecida pela qualidade de seu modelo de gestão. Atualmente possui 21 funcionários;

- Allumé Cosméticos: empresa sediada em Santana de Parnaíba - SP, fabricante de produtos cosméticos destinados ao mercado de profissionais de beleza. Fundada em 1979, passou por uma completa reestruturação

VOGEL, J.; WOOD JUNIOR, T. Práticas gerenciais de pequenas empresas industriais do Estado de São Paulo: um estudo exploratório. Revista de Empreendedorismo e Gestão 
em 2002, quando seu atual diretor presidente assumiu o controle da empresa. Atualmente possui 20 funcionários;

- Attivos Magisttrais: empresa sediada em Santana de Parnaíba - SP, fabricante e fornecedora de insumos para a indústria farmacêutica, além de atuar em pesquisa e desenvolvimento de fitoterápicos de plantas nacionais. Fundada em 2002, tem profissionalizado sua gestão e crescido a taxas elevadas nos últimos anos. Atualmente possui 97 funcionários;

- Rubberart: empresa sediada em São Paulo - SP, fabricante de artigos técnicos de borracha, é líder no fornecimento de artigos de vedação especializados para a indústria hidromecânica. Fundada em 1951, figurou entre as 250 PME's que mais cresceram no período entre 2008 e 2010 (Delloitte e Exame PME, 2011). Atualmente possui 63 funcionários.

A partir das transcrições das entrevistas e registros realizados pelo pesquisador, os temas abordados foram classificados de acordo com categorias identificadas. Foi realizada uma tabulação das respostas obtidas nas entrevistas com o intuito de agrupar e organizar as principais ideias surgidas.

\section{Resultados}

Os resultados alcançados nesta pesquisa foram analisados em conformidade com os objetivos do trabalho e estão apresentados nas subseções seguintes.

\section{Definição de Práticas Gerenciais}

A primeira pergunta feita aos entrevistados foi: "o que você entende por práticas gerenciais?". As respostas similares foram consolidadas, resultando na seguinte definição:

Práticas gerenciais são atividades e procedimentos adotados para administrar a empresa e coordenar seus recursos, com o intuito de

VOGEL, J.; WOOD JUNIOR, T. Práticas gerenciais de pequenas empresas industriais do Estado de São Paulo: um estudo exploratório. Revista de Empreendedorismo e Gestão 
atingir os objetivos da organização (e.g. melhorar seu desempenho, aumentar a lucratividade e gerar eficiência). Incluem, entre outros, a gestão de recursos humanos, os controles financeiros, a administração de vendas, a gestão de produtos e mercados, e a estratégia e operações.

\section{Práticas Gerenciais}

Apresentamos a seguir, as principais práticas gerenciais adotadas pelas quatro empresas estudadas, agrupadas em nove temas de gestão. Para esta apresentação optou-se por utilizar uma estrutura semelhante à do questionário do Observatório de Gestão (BRITO; WOOD, 2009), que traz uma lista abrangente dos aspectos de gestão relevantes de uma empresa industrial.

\section{Planejamento Estratégico}

De forma geral, não se verificou um processo de planejamento estratégico formal nas empresas estudadas. A maioria das decisões estratégicas é tomada pelos proprietários de forma centralizada e não sistemática. A maioria dos entrevistados alega falta de tempo como razão para deixar de realizar o planejamento estratégico de forma estruturada. Com relação ao posicionamento estratégico, percebe-se que a maioria das empresas analisadas optou pela atuação em nichos específicos de mercado, que demandam algum nível de especialização e, ao mesmo tempo, não são considerados atrativos para empresas de grande porte.

\section{Operações e Logística}

Todas as empresas analisadas contam com controles operacionais básicos, como a prática de estoques mínimos de segurança, por exemplo. Porém, estes variam bastante em seu grau de sofisticação. Algumas empresas planejam a produção manualmente, outras utilizam controles visuais de níveis de estoque no

VOGEL, J.; WOOD JUNIOR, T. Práticas gerenciais de pequenas empresas industriais do Estado de São Paulo: um estudo exploratório. Revista de Empreendedorismo e Gestão de Pequenas Empresas, v. 1, n.2, 2012. 
almoxarifado e algumas empregam sistemas informatizados sofisticados, comparáveis aos utilizados por grandes empresas. O uso de sistemas de gestão integrados (ERP) parece estar ganhando importância como ferramenta de gestão operacional.

A sistematização dos controles e a integração entre os diversos processos (compras, produção, vendas, etc.) permite antecipar e prevenir a falta de produtos, além de possibilitar um planejamento de produção mais eficiente que aperfeiçoa a alocação dos recursos e reduz os prazos de entrega aos clientes.

\section{Gestão de Clientes}

As empresas estudadas realizam pouca pesquisa de mercado junto aos clientes ou consumidores finais de seus produtos. A forma mais utilizada para manter contato com o mercado e ouvir os clientes é por meio da participação em feiras e eventos específicos do setor. Por outro lado, é comum o envolvimento direto dos proprietários na atividade comercial, o que os aproxima do mercado e cria um canal de comunicação direta com os clientes. Outras formas de marketing comuns às pequenas indústrias analisadas são a divulgação da empresa ou do produto em revistas especializadas e a contratação de assessorias de imprensa.

\section{Inovação}

Duas das empresas analisadas dependem de fornecedores para desenvolvimento de novas tecnologias e patentes. Elas alegam não ter capacidade de manter uma estrutura própria de pesquisa e desenvolvimento. Por outro lado, a empresa de fármacos e a empresa de aquecedores desenvolveram patentes e tecnologias próprias. Em ambos os casos, os proprietários das empresas possuem um perfil técnico. Suas práticas de inovação tecnológica são comparáveis a empresas de maior porte, contemplando um laboratório de pesquisa e 
desenvolvimento, parcerias com universidades e a busca constante por oportunidades de inovação.

\section{Monitoramento de Resultados e Sistema de Incentivo}

Os gestores das empresas estudadas acompanham indicadores, tais como: a evolução do volume de vendas e de produção, a quantidade de retrabalho na fabricação dos produtos, índices de qualidade no fornecimento, etc. As metas são definidas com base no histórico de anos anteriores e consideram impactos possíveis de investimentos em melhoria de processos. Por outro lado, apesar de considerado relevante, o uso de sistemas de incentivo ao desempenho não está disseminado entre as empresas estudadas, exceto pela área comercial, na qual a maior parte da remuneração é variável e atrelada às vendas.

\section{Gestão de Recursos Humanos}

As empresas estudadas dependem muito de seus quadros, pois há poucos procedimentos escritos, suas estruturas são enxutas e o acúmulo de funções é comum. Durante a pesquisa, os entrevistados destacaram questões relacionadas ao ambiente de trabalho e ao desenvolvimento. Segundo eles, seus funcionários prezam o bom ambiente de trabalho e o contato direto com o proprietário. Com relação a treinamento e desenvolvimento, a maior parte das iniciativas ocorre sob demanda, conforme necessidade do cargo. Algumas empresas subsidiam os estudos dos funcionários, arcando com uma parte do custo, enquanto outras oferecem curso de alfabetização gratuitamente. Tais iniciativas reforçam o vínculo entre empresa e funcionário.

VOGEL, J.; WOOD JUNIOR, T. Práticas gerenciais de pequenas empresas industriais do Estado de São Paulo: um estudo exploratório. Revista de Empreendedorismo e Gestão 
Gestão Financeira

A maioria das empresas estudadas utiliza o controle de fluxo de caixa, porém nem todas fazem projeções futuras. A ausência dessa prática implica frequentemente em situações emergenciais, nas quais a empresa acaba recorrendo a recursos caros para poder honrar com seus compromissos de pagamentos. Em relação ao planejamento tributário, a maioria dos entrevistados delega essa função a um contador externo. Em relação a métricas de retorno ao acionista, na maioria dos casos os proprietários não apuram indicadores financeiros de forma precisa, mas estabelecem uma retirada mensal para os sócios, sendo o restante reinvestido na empresa.

\section{Relacionamento com Grupos de Interesse}

De acordo com os entrevistados, o pequeno porte do negócio não é suficiente para chamar a atenção da mídia, de ONG's e de outros possíveis grupos de interesse. O universo de relações acaba se limitando ao sindicato, onde a empresa negocia os acordos coletivos e o dissídio anual. Relaciona-se ainda aos diversos órgãos de fiscalização (Anvisa, Polícia Federal, Exercito, Cetesb etc.), que são vistos de forma crítica pela imposição de controles que levam a um excessivo trabalho burocrático.

\section{Sustentabilidade}

A maioria das empresas estudadas declara se limitar a atender a legislação em vigor, não apresentando um posicionamento específico a respeito do assunto. Por outro lado, foram identificadas iniciativas ligadas a desenvolvimento de produtos mais sustentáveis, associados à reciclagem de resíduos e à redução de poluentes. Duas empresas declararam atuar em mercados voltados à sustentabilidade, já que

VOGEL, J.; WOOD JUNIOR, T. Práticas gerenciais de pequenas empresas industriais do Estado de São Paulo: um estudo exploratório. Revista de Empreendedorismo e Gestão 
sua atividade contribui com projetos de energia limpa e renovável. Em uma das empresas, o desenvolvimento de novos produtos prioriza insumos que não agridem o meio ambiente.

\section{Sumário}

O quadro 1 sumariza as principais características gerenciais das empresas estudadas em cada uma das nove práticas analisadas. A terceira coluna traz trechos escolhidos das entrevistas.

Quadro 1 - Principais Práticas Gerenciais Adotadas pelas Empresas Estudadas. 


\section{REVISTA}

\section{REGEPE}

\section{A Revista da ANEGEPE}

e Gestảo de Pequenas Empresas

\section{www.regepe.org.br}

\begin{tabular}{|c|c|c|}
\hline Área de gestão & Descrição dos principais resultados & Evidências \\
\hline $\begin{array}{l}\text { Planejamento } \\
\text { Estratégico }\end{array}$ & $\begin{array}{l}\text { - Processo formal quase inexistente. } \\
\text { - Condução intuitiva e pouco documentada, } \\
\text { realizada pelos proprietários. }\end{array}$ & $\begin{array}{l}\text { "Questão estratégica tá na minha mão... se algum dia eu morrer, acho } \\
\text { que a empresa continua andando por algum tempo com o que ela tem, } \\
\text { mas ela depende de mim pra criar coisas novas (...) meus gerentes são } \\
\text { muito bons nas funções deles, mas eles não têm a visão estratégica } \\
\text { geral (...) só eu que enxergo o todo." }\end{array}$ \\
\hline $\begin{array}{l}\text { Operações } \\
\text { logística }\end{array}$ & $\begin{array}{l}\text { - Busca de práticas modernas de } \\
\text { manufatura. } \\
\text { - Tendência de incorporação de sistemas } \\
\text { integrados de gestão. }\end{array}$ & $\begin{array}{l}\text { "A gente tinha muita falta de produto. Hoje, a partir do momento que o } \\
\text { pedido entrou, ele (o novo sistema ERP) considera o produto como } \\
\text { reservado; então a gente consegue tomar decisões de produção antes } \\
\text { mesmo de o produto estar faltando." }\end{array}$ \\
\hline $\begin{array}{l}\text { Gestão } \\
\text { clientes }\end{array}$ & $\begin{array}{l}\text { - Presença de foco no cliente. } \\
\text { - Proprietários tem papel de protagonistas } \\
\text { no relacionamento com clientes. }\end{array}$ & $\begin{array}{l}\text { "A gente não faz pesquisas periódicas formais. O que a gente faz é, uma } \\
\text { vez por ano, um evento nacional (do qual a maioria dos clientes } \\
\text { participa) e a gente passa três dias fazendo uma reunião que serve } \\
\text { tanto pra apresentar novos lançamentos quanto para discutir como está } \\
\text { a área comercial, dificuldades, sugestões." }\end{array}$ \\
\hline Inovação & $\begin{array}{l}\text { - Inovações implementadas como } \\
\text { respostas às demandas de clientes e } \\
\text { oportunidades de mercado. } \\
\text { - Existência de casos de desenvolvimento } \\
\text { tecnológico, conduzido por meio de parcerias } \\
\text { com universidades e fornecedores. }\end{array}$ & $\begin{array}{l}\text { "(...) não tem uma verba de investimento interno nosso em novas } \\
\text { tecnologias; a gente depende dos nossos fornecedores. A gente não } \\
\text { tem capacidade de fazer inovações tecnológicas." }\end{array}$ \\
\hline $\begin{array}{l}\text { Monitoramento } \\
\text { de resultados e } \\
\text { sistema de } \\
\text { incentivo }\end{array}$ & $\begin{array}{l}\text { - Uso razoavelmente disseminado de } \\
\text { indicadores para definição e monitoramento } \\
\text { de metas. } \\
\text { - Uso restrito de sistemas de incentivo } \\
\text { ligados ao desempenho }\end{array}$ & $\begin{array}{l}\text { "cheguei uma época a estipular metas e pagar uma bonificação em } \\
\text { dinheiro pro pessoal da fábrica, mas cortei isso porque o pessoal achava } \\
\text { que fazia parte do salário e em meses que não tinha eles ficavam } \\
\text { bravos." }\end{array}$ \\
\hline
\end{tabular}

Fonte: Os Autores, 2012.

VOGEL, J.; WOOD JUNIOR, T. Práticas gerenciais de pequenas empresas industriais do Estado de São Paulo: um estudo exploratório.

Revista de Empreendedorismo e Gestão de Pequenas Empresas, v. 1, n.2, 2012. 130 


\section{REVISTA}

\section{REGEPG}

Revista de Empteendedorismo

e Geståo de Pequenas Empresa:

\section{A Revista da ANEGEPE}

www.regepe.org.br

\begin{tabular}{|c|c|c|}
\hline $\begin{array}{l}\text { Gestão } \\
\text { recursos } \\
\text { humanos }\end{array}$ & $\begin{array}{l}\text { - Gestão de recursos humanos } \\
\text { caracterizada pelo foco na preservação do } \\
\text { vínculo funcionário-empresa. } \\
\text { - Existência de iniciativas de capacitação } \\
\text { básica e desenvolvimento. }\end{array}$ & $\begin{array}{l}\text { "Muita gente já recebeu propostas melhores, e acabou continuando por } \\
\text { essa proximidade, por esse aspecto mais humano (...) e o clima } \\
\text { também ajuda muito, o companheirismo (...)". }\end{array}$ \\
\hline Gestão financeira & $\begin{array}{l}\text { - Controle financeiro realizado diretamente } \\
\text { pelo acionista; tomada de decisão } \\
\text { centralizada e intuitiva. } \\
\text { - Ausência de métricas de gestão de valor } \\
\text { para o acionista e uso limitado de } \\
\text { ferramentas de orçamento. }\end{array}$ & $\begin{array}{l}\text { "A gente estabeleceu uma retirada pros acionistas, quase como um } \\
\text { salário e o restante é reinvestido na empresa (...) a gente só tem um } \\
\text { balanço que é fechado trimestralmente pelo contador que não } \\
\text { necessariamente é um balanço gerencial que a gente consiga usar (...)". }\end{array}$ \\
\hline \begin{tabular}{lr} 
& \multicolumn{2}{c}{ Relacion } \\
amento & com \\
grupos & de \\
interesse &
\end{tabular} & $\begin{array}{l}\text { - Postura reativa em relação aos grupos de } \\
\text { interesse. } \\
\text { - Relacionamento com sindicatos e } \\
\text { agências reguladoras. }\end{array}$ & $\begin{array}{l}\text { "(...) tem os órgãos fiscalizadores e, infelizmente, tudo é muito } \\
\text { burocrático (...) eu gasto muito tempo e dinheiro com esses órgãos." }\end{array}$ \\
\hline
\end{tabular}

Quadro 1 (cont.): Principais Práticas Gerenciais Adotadas pelas Empresas Estudadas.

Fonte: Os Autores, 2012.

VOGEL, J.; WOOD JUNIOR, T. Práticas gerenciais de pequenas empresas industriais do Estado de São Paulo: um estudo exploratório.

Revista de Empreendedorismo e Gestão de Pequenas Empresas, v. 1, n.2, 2012. 


\section{Discussão}

Nesta seção é apresentada a discussão dos principais resultados encontrados na pesquisa, organizados em torno de quatro temas: as similaridades entre as empresas, o perfil do empresário, a questão da gestão financeira e o impacto das práticas gerenciais.

\section{Empresas que Apresentam Algumas Práticas e Condutas Similares}

Apesar de exibirem diversidade em termos de ramo de atuação, produtos, tecnologia e perfil, as empresas estudadas apresentam algumas características comuns. Em relação à gestão de operações, percebe-se uma tendência crescente à utilização de sistemas integrados de gestão (ERP). Todas as empresas estudadas haviam implementado ou modificado seu ERP recentemente, o que demonstra a importância de um fluxo de informações ágil e preciso para tornar o negócio eficiente e apoiar o processo de tomada de decisões. Tal resultado é coerente com a literatura científica que vem apontando a importância de tais sistemas para pequenas empresas, embora também ressalte dificuldades de implantação (e.g. MENDES; ESCRIVÃO FILHO, 2002).

Quanto à gestão de recursos humanos, as empresas estudadas apresentam práticas que, apesar de frequentemente informais, demonstram eficácia na atração, retenção e desenvolvimento do capital humano. Os principais elementos identificados foram: a criação de um ambiente de trabalho colaborativo, a proximidade com o proprietário e a possibilidade de desenvolvimento profissional por mérito. Tais fatores contribuem para uma baixa rotatividade de funcionários e para a retenção do conhecimento gerado internamente aumentando assim, a produtividade da mão de obra e reduzindo custos com seleção e treinamento de pessoal. Tal resultado contrapõe-se aqueles encontrados por Padrão, Motta e Vieira (2009), que apontaram práticas defasadas nas empresas industriais brasileiras, quando

VOGEL, J.; WOOD JUNIOR, T. Práticas gerenciais de pequenas empresas industriais do Estado de São Paulo: um estudo exploratório. Revista de Empreendedorismo e Gestão de Pequenas 
comparadas às de outros países. Naturalmente, o resultado da presente pesquisa pode ter sido influenciado pela escolha de empresas de sucesso.

Outra característica comum às empresas estudadas é a adoção de uma perspectiva de análise do tipo custo-benefício para analisar a adoção de determinadas práticas gerenciais, usualmente consideradas como boas práticas. De fato, diversos empresários deixam de adotar boas práticas gerenciais por considerarem seu custo superior ao benefício. Tal resultado é similar ao encontrado por Davig et al. (2003), que estudaram 75 pequenas empresas industriais norteamericanas e constataram que $70 \%$ dos empresários pesquisados reconhecem que os programas de qualidade total (TQM) contribuem para melhorar a satisfação do cliente e a reputação da empresa, no entanto, implicam em maiores custos operacionais.

\section{A influência do Perfil do Proprietário nas Práticas Gerenciais}

Um ponto comum a todas as empresas analisadas é o fato de os proprietários, apesar de centralizarem as decisões estratégicas e a gestão financeira, terem sido capazes de delegar as funções operacionais. Em pesquisas que abordam as características gerais de pequenas empresas, é recorrente a menção à centralização da gestão pelos proprietários (CARVALHO; BOTELHO; CAMPANHOL, 2003, TORRÉS; JULIEN, 2005, CARPES; TRICHES; PILATTI, 2012). Em contrapartida, pesquisas que analisaram as características de pequenas empresas de rápido crescimento as diferenciam por terem desenvolvido uma estrutura organizacional interna capaz de permitir que o líder delegue as responsabilidades operacionais e possa focar nas funções estratégicas (SMALLBONE; LEIG; NORTH, 1995, FULLER-LOVE, 2006). Portanto, percebe-se mais um ponto de convergência entre a literatura e a prática observada nas empresas estudadas.

VOGEL, J.; WOOD JUNIOR, T. Práticas gerenciais de pequenas empresas industriais do Estado de São Paulo: um estudo exploratório. Revista de Empreendedorismo e Gestão de Pequenas 
Somando-se a isto, pode-se afirmar que práticas gerenciais nas pequenas empresas estudadas tendem a variar de acordo com o perfil e a formação profissional de seus proprietários. Nas empresas em que o proprietário é um administrador profissional, há maior ênfase na gestão de finanças, recursos humanos e operações. Por outro lado, naquelas em que o proprietário tem formação técnica, o processo de inovação em produtos se mostrou mais presente, enquanto a gestão financeira era deixada em segundo plano. A gestão da sustentabilidade é outro tema que sofre influência direta do perfil dos proprietários, refletindo seus valores pessoais.

\section{Gestão Financeira: Tema Crítico Recorrente}

A gestão financeira foi considerada pela maioria dos entrevistados como a prática mais crítica para o sucesso e a sobrevivência das empresas. No entanto, é também a prática que apresenta as maiores deficiências nas empresas estudadas. De fato, a literatura aponta a má gestão financeira como uma das principais causas de mortalidade das empresas jovens (THORNHILL; AMIT, 2003).

Tais práticas apresentam alto grau de dificuldade, exigindo conhecimento técnico específico. No entanto, muitos proprietários não estão dispostos a adquirir tal conhecimento. Outro entrave para o desenvolvimento desta prática é a resistência de muitos proprietários em delegar a gestão financeira a profissionais por falta de confiança (FULLER-LOVE, 2006). Tal postura pode vir a limitar o crescimento, pois a ausência de práticas consagradas de gestão financeira inibem aportes de capital e investimentos externos.

Entre as quatro empresas estudadas, apenas uma adota práticas gerenciais avançadas na área financeira. Significativamente, seu proprietário tem formação neste campo. A maioria das empresas estudadas utiliza apenas o caixa como principal indicador de desempenho financeiro, confirmando as conclusões da pesquisa de Jarvis et al. (2000), realizada junto a pequenas empresas. Nas demais

VOGEL, J.; WOOD JUNIOR, T. Práticas gerenciais de pequenas empresas industriais do Estado de São Paulo: um estudo exploratório. Revista de Empreendedorismo e Gestão de Pequenas 
empresas, ficaram nítidas as deficiências na gestão financeira. Alguns empresários relataram que estão buscando melhorar seus controles.

\section{Práticas Gerenciais e a Influência no Desempenho da Empresa}

O caráter exploratório da presente pesquisa não buscou comprovar, de forma determinística, o impacto das práticas gerenciais sobre o desempenho. No entanto, foi possível colher algumas evidências que sugerem tal relação. Por exemplo, observou-se na pesquisa de campo que as empresas que realizam uma gestão eficaz de recursos humanos apoiam o desenvolvimento profissional de seus funcionários e buscam oferecer boas condições de trabalho, fortalecendo o vínculo entre empresa e funcionários. Com isso, geram impactos positivos verificáveis sobre o absenteísmo e a rotatividade da mão de obra (PAJO; COETZER; GUENOLE, 2010, SELS et al., 2006), além de perceberem ganhos em termos de produtividade, comprometimento e proatividade no relacionamento com clientes.

Tal resultado corrobora com a literatura existente, segundo a qual a adoção de práticas gerenciais adequadas tem impacto positivo sobre o desempenho (FENING; PESAKOVIC; AMARIA, 2008) e aumenta a probabilidade de sobrevivência das pequenas empresas (MIZUMOTO et al., 2010, THORNHILL; AMIT, 2003).

\section{Conclusão}

Antes de tudo, vale ratificar que a presente pesquisa teve como objetivo verificar como proprietários e gestores de pequenas empresas industriais bem sucedidas definem práticas gerenciais, e ainda identificar quais práticas eles adotam. Para isso, foram estudadas quatro pequenas empresas industriais de sucesso com destaque em seus setores de atuação, seja pela qualidade de sua

VOGEL, J.; WOOD JUNIOR, T. Práticas gerenciais de pequenas empresas industriais do Estado de São Paulo: um estudo exploratório. Revista de Empreendedorismo e Gestão de Pequenas 
gestão ou por terem apresentado um crescimento acelerado e sustentável nos últimos anos.

Observou-se que as empresas analisadas têm investido no aprimoramento de seus modelos de gestão, buscando adotar ferramentas sofisticadas, como os sistemas integrados de gestão (ERP's), por exemplo. Há consciência de que este tipo de ferramenta traz benefícios diretos, estimula a busca pela melhoria contínua e aproxima o modelo de gestão das pequenas empresas daqueles de grandes organizações modernas.

Em contrapartida, as pequenas empresas analisadas apresentam processos pouco formais. Em muitos casos, ocorre sobreposição de funções e concentração de atividades em alguns indivíduos. Outra característica relevante é a centralização das decisões no proprietário. Tal condição confere agilidade, porém pode em médio prazo frear o desenvolvimento da empresa.

Apesar das oportunidades de mercado e das possibilidades de expansão, verificou-se que nem todos os empresários almejam o crescimento de suas empresas. Alguns entrevistados apontam como vantagem competitiva o fato de a empresa ser ágil, flexível e poder manter o controle da gestão centralizado no proprietário. Outros entrevistados mencionam a estrutura tributária no Brasil e a maior regulamentação imposta a empresas de médio e grande porte como fatores que inibem o crescimento de seus negócios, na medida em que aumentam as obrigações da empresa e reduzem sua competitividade.

Acredita-se que a realização desta pesquisa possa contribuir para o desenvolvimento do conhecimento sobre pequenas empresas no Brasil e para a prática empresarial. Em relação ao primeiro ponto, o estudo apresentou a aplicação do modelo de Bloom e Van Reenen (2007), originalmente aplicado a empresas de porte médio, demonstrando que ele pode também ser empregado à análise de empresas de pequeno porte. Em relação ao segundo ponto, o estudo apresentou um retrato das práticas gerenciais de pequenas empresas industriais, que pode ser útil para a realização de diagnósticos e identificação de oportunidades de melhoria.

VOGEL, J.; WOOD JUNIOR, T. Práticas gerenciais de pequenas empresas industriais do Estado de São Paulo: um estudo exploratório. Revista de Empreendedorismo e Gestão de Pequenas 
A opção pela realização de uma pesquisa exploratória, coerente com o objetivo primordial desta, implicou, entretanto, em algumas limitações para o estudo. A primeira limitação refere-se ao pequeno número de empresas pesquisadas, o que reduziu o número de observações. A segunda limitação refere-se ao número de entrevistas, as quais se restringiram ao topo de cada organização.

Em função destas limitações, surgem possibilidades para futuros estudos: primeiro, ampliar o número de casos estudados de forma a enriquecer o retrato das práticas gerenciais; segundo, realizar o estudo também com pequenas empresas de serviço, avaliando semelhanças e diferenças; e terceiro, realizar um amplo estudo quantitativo, a partir de hipóteses definidas em estudos qualitativos, visando colher resultados generalizáveis para a população de pequenas empresas.

\section{Referências}

ANDERSSON, S.; TELL, J. The relationship between the manager and growth in small firms. Journal of Small Business and Enterprise Development, v.16, n.4, p. 586-598, 2009.

BARRINGER, B. R.; JONES, F. F.; NEUBAUM, D.O. A quantitative content analysis of the characteristics of rapid-growth firms and their founders. Journal of Business Venturing, v. 20, p. 663-687, 2005.

BLOOM, N.; VAN REENEN, J. Measuring and explaining management practices across firms and countries. Quarterly Journal of Economics, v. 122, n.4,p. 13511408, 2007.

BRITO, L.; WOOD JR. T. Observatório de Gestão: Práticas Gerenciais em Empresas Brasileiras. GVPesquisa, 2009.

CARPES, A. M. S.; TRICHES, A. M.; PILATTI, G. C. Controles contábeis e gerenciais utilizados pelas pequenas indústrias do setor moveleiro. IN: ENCONTRO DE ESTUDOS SOBRE EMPREENDEDORISMO E GESTÃO DE PEQUENAS EMPRESAS, 7., 2012, Florianópolis, Anais... Florianópolis: ANEGEPE, FURB, UNIVALI, UDESC, 2012.

VOGEL, J.; WOOD JUNIOR, T. Práticas gerenciais de pequenas empresas industriais do Estado de São Paulo: um estudo exploratório. Revista de Empreendedorismo e Gestão de Pequenas 
CARVALHO NETO, S.; BOTELHO Jr., A. C.; CAMPANHOL, E. M. Cultura e gestão na pequena empresa: o estilo de administrar do pequeno industrial calçadista. In: ENCONTRO DE ESTUDOS SOBRE EMPREENDEDORISMO E GESTÃO DE PEQUENAS EMPRESAS, 3., Brasília. Anais...Brasília: UEL/UNB, 2003.

CHRISMAN, J. J.; KELLERMANNS, F. W. CHAN, K. C.; LIANO, K. Intellectual foundations of current research in family business: An identification and review of 25 influential articles. Family Business Review, v.23, p. 9-26, 2010.

CHRISMAN, J. J.; BAUERSCHMIDT, A.; HOFER, C.W. The Determinants of New Venture Performance An Extended Model. Entrepreneurship: Theory and Practice, v. 23, 1998.

DAVIG, W. et al. Quality management in small manufacturing. Industrial Management \& Data Systems, v. 103, n.2, p. 68-77, 2003.

DEBICKI, B. J. et al. Family business research in the new millennium: An overview of the who, the where, the what, and the why. Family Business Review, v. 22, p. 151166, 2009.

DELLOITTE; EXAME PME. Um estudo sobre as PME's que mais crescem no Brasil, 2011. Disponível em: <http://www.deloitte.com/assets/DcomBrazi//Local\%20Assets/Documents/Estudos\%20e\%20pesquisas/PMEsMaisCrescem 2011.pdf>. Acesso em: 06 jun. 2012.

DUNDON T.; RYAN P. Interviewing Reluctant Respondents: Strikes, Henchmen, and Gaelic Games. Organizational Research Methods, v.13, n.3, p. 562-581, 2010.

FENING, F. A.; PESAKOVIC, G.; AMARIA, P. Relationship between quality management practices and the performance of small and medium size enterprises (SMEs) in Ghana. International Journal of Quality \& Reliability Management, v.25, n.7, p. 694-708, 2008.

FNQ. Critérios de excelência 2010. Fundação Nacional da Qualidade, 2009. Disponível em: <http://www.fnq.org.br>. Acesso em: 12 mai. 2011.

FULLER-LOVE, N. Management development in small firms. International Journal of Management Reviews, v. 8, n.3, p.175-90, 2006.

VOGEL, J.; WOOD JUNIOR, T. Práticas gerenciais de pequenas empresas industriais do Estado de São Paulo: um estudo exploratório. Revista de Empreendedorismo e Gestão de Pequenas 
GRAY, C. Entrepreneurship, resistance to change and growth in small firms. Journal of Small Business and Enterprise Development, v. 9, n.1, p. 61-72, 2002.

JARVIS, R. et al. The use of quantitative and qualitative criteria in the measurement of performance in small firms. Journal of Small Business and Enterprise Development, v. 7, n. 2, 2000.

MENDES, J. V.; ESCRIVÃO FILHO, E. Sistemas integrados de gestão ERP em pequenas empresas: um confronto entre o referencial teórico e a prática empresarial. Gestão \& Produção, v.9, n.3, p.277-296, 2002.

MIZUMOTO, F. M. et al. O impacto de capital humano, capital social e práticas gerenciais na sobrevivência de empresas nascentes: um estudo com dados de pequenas empresas no Estado de São Paulo. Revista de Administração da USP, v. 45, n. 4, p. 343-355, out./nov. 2010.

PADRÃO L. C.; MOTTA C.; VIEIRA J. T. Aplicação das práticas de gestão em empresas manufatureiras de pequeno e médio porte. In: SIMPÓSIO DA ADMINISTRAÇÃO DA PRODUÇÃO, LOGÍSTICA E OPERAÇÕES INTERNACIONAIS, 12., 2009, São Paulo. Anais... São Paulo: FGV/EAESP, 2009.

PAJO, K.; COETZER, A.; GUENOLE, N. Formal development opportunities and withdrawal behaviors by employees in small and medium-sized enterprises. Journal of Small Business Management, v. 48, n.3, p. 281-30, 2010.

REIJONEN, H.; KOMPPULA R. Perception of success and its effect on small firm performance. Journal of Small Business and Enterprise Development, v.14, n.4, p.689-701, 2007.

SEBRAE; DIEESE. Anuário do trabalho na micro e pequena empresa: 2009, 3a. Ed.. SEBRAE (Org.); Brasília: DIEESE, 2010.

SEBRAE-SP. Doze anos de monitoramento da sobrevivência e mortalidade de empresas (Agosto/2010). Disponível em:

VOGEL, J.; WOOD JUNIOR, T. Práticas gerenciais de pequenas empresas industriais do Estado de São Paulo: um estudo exploratório. Revista de Empreendedorismo e Gestão de Pequenas 
<http://www.SEBRAEsp.com.br/TenhoUmaEmpresa/Biblioteca/OutrosConteudos/Est udosEPesquisas/MortalidadeDasEmpresas/Paginas/MortalidadeDasEmpresas.aspx >. Acesso em: 05 jan. 2011.

SELS, L. et al. Linking HRM and small business performance: an examination of the impact of HRM intensity on the productivity and financial performance of small businesses. Small Business Economics, v. 26, n.1, p. 83-101, 2006.

SMALLBONE, D.; LEIG, R.; NORTH, D. The characteristics and strategies of high growth SMEs. International Journal of Entrepreneurial Behavior \& Research, v.1, n.3, p.44-62, 1995.

THORNHILL, S.; AMIT, R. Learning about failure: bankruptcy, firm age, and the resource-based view. Organization Science, Linthicum, v. 14, n. 5, p.497-509, Oct. 2003.

TORRÈS, O.; JULIEN, P. A. Specificity and denaturing of small business. International Small Business Journal, v. 23, n. 4, p.355-377, 2005.

WOOD Jr. T.; CALDAS, M. P. Empresas brasileiras e o desafio da competitividade. RAE Eletrônica, v. 47, n. 3, p. 66-78, 2007.

XHENETI, M.; BLACKBURN, R. Small business and entrepreneurship (SBE): An analysis of publications and implications for the development of the field. In: Rencontres de St-Gall 2010: Strategic Entrepreneurship - The Promise for Future Entrepreneurship, Family Business and SME Research?; 06 - 08 Sep 2010.

Recebido em 02/08/2012. Aprovado em 17/10/2012.

VOGEL, J.; WOOD JUNIOR, T. Práticas gerenciais de pequenas empresas industriais do Estado de São Paulo: um estudo exploratório. Revista de Empreendedorismo e Gestão de Pequenas 